Contributed Paper for IBMM-90, to be published in Nuclear Instruments and Methods B

\title{
Laser-Induced Fluorescence and Nonlinear Optical Properties of Ion-Implanted Fused Silica
}

K. Becker, L. Yang, R. F. Haglund, Jr. Department of Physics and Astronomy

Vanderbilt University, Nashville, TN 37235 USA

R. H. Magruder and R. A. Weeks

Department of Materials Science and Engineering

Vanderbilt University, Nashville, TN 37235 USA

R. A. Zuhr

Solid-State Division

Oak Ridge National Laboratory, Oak Ridge, TN 37831 USA

\begin{abstract}
We report absorption, fluorescence and nonlinear optical properties of fused silica implanted with $\mathrm{Ti}, \mathrm{Cu}$ and $\mathrm{Bi}$ and doses of $1 \cdot 10^{15} \mathrm{ions} / \mathrm{cm}^{2}$ to $6 \cdot 10^{16} \mathrm{ions} / \mathrm{cm}^{2}$ when irradiated with $532 \mathrm{~nm}$ laser light. The fluorescence spectrum is a broad band around $640 \mathrm{~nm}$ and shows little variation for all ion species. Absorption as function of implanted dose shows a threshold for $\mathrm{Ti}$ between $1 \cdot 10^{16} \mathrm{ions} / \mathrm{cm}^{2}$ and $6 \cdot 10^{16} \mathrm{ions} / \mathrm{cm}^{2}$. The nonlinear optical index is large, $\mathrm{n}_{2}>10^{-5}$ esu. All measured quantities show a strong dependence on the implanted ion dose. The source of the nonlinearity, whether electronic or thermal, remains to be more completely determined.
\end{abstract}

CONF-900936--23

DE91 004523

Corresponding Author: Dr. Klaus Becker, Department of Physics and Astronomy, Vanderbilt University, Nashville, TN 37235, Tel. 615-322-2828; FAX 615-343-7263. 


\section{Introduction and Motivation}

Ion implantation has been used to alter electronic, thermal and mechanical properties of substrates. During the last two decades, the growth of optical communications technology has also motivated research on modification of the linear index of refraction of dielectrics in order to make waveguides for optical carrier signa!s [1]. However, significantly less attention has been paid to other optical properties of ion-implanted dielectrics, even though this technology offers a number of advantages in control of electronic structure and gross optical properties of the implanted region. In this paper we present a number of results relevant to the possible use of ion-implanted fused silica in active optical devices and circuits, including intensity-dependent absorption, laser-induced fluorescence and ion-species-dependent nonlinear susceptibility.

\section{Sample Preparation and Characterization}

High-purity silica discs, $1 \mathrm{~mm}$ thick, $20 \mathrm{~mm}$ diameter, were used as substrates for implantation. The manufacturer of the silica (Thermal American, Inc.) lists total cation impurities as $<200 \mathrm{ppm} \mathrm{H}_{2}$ by weight, all others $<10 \mathrm{ppm}$. The principal anion impurity is $\mathrm{Cl}$, comprising about $80 \mathrm{ppm}$ by weight. The surfaces of the discs were polished to optical quality, then cleaned with ethyl alcohol and distilled water and dried in ambient laboratory air prior to implantation. The disks were implanted with $160 \mathrm{keV}$ Ti ions at an average current of $2 \mu \mathrm{A} / \mathrm{cm}^{2}$. At this current density, the temperature of the substrate remains below $35^{\circ} \mathrm{C}$. The concentration of ions as a function of depth in the substrate was measured by Rutherford backscattering. For $\mathrm{Ti}$ and $\mathrm{Bi}$ it is approximately a Gaussian function with the maximum at $120 \mathrm{~nm}$ below the surface and $140 \mathrm{~nm}$ full-width at halfmaximum. For $\mathrm{Cu}$ and doses $>3 \cdot 10^{16}$ ions $/ \mathrm{cm}^{2}$, the depth profile is bimodal, with peaks at about $90 \mathrm{~nm}$ and $170 \mathrm{~nm}$. Some samples were implanted on both sides.

The electronic state of the implanted ions is less well characterized. For doses $>5 \cdot 10^{15}$ ions $/ \mathrm{cm}^{2}$, the fraction of $\mathrm{Ti}$ in the $3+$ state, as measured by electron paramagnetic 
resonance and optical absorption spectroscopy, is $>10 \%$. The fraction decreases with increasing dose [2]. Implanted $\mathrm{Cu}$ may be neutral, in the $2+$ state, or aggregated as colloids 13]. The implantation process also produces defects in the implantation zone. In silica the most prominent defects are $E^{\prime}$ centers, non-bridging oxygen-hole centers and peroxy molecular ions [4]. Concentration of these defects varies with implanted ion species $[5,6]$. In case of $\mathrm{Ti}$ the $\mathrm{E}^{\prime}$ centers have the highest concentration of all defects for doses $>5 \cdot 10^{15} \mathrm{ions} / \mathrm{cm}^{2}$. Since these defects also have a spectrum of optical transitions, it is critical to understand the role they may play in the optical properties of the implanted zone.

\section{Experimental apparatus}

The light source was a mode-locked, frequency-doubled Nd:YAG laser $(532 \mathrm{~nm}$, 100 ps FWHM pulse width, $76 \mathrm{MHz}$ pulse repetition rate, $1.8 \mathrm{~W}$ maximum average power). At this wavelength $\mathrm{Bi}-, \mathrm{Ti}$ - and $\mathrm{Cu}$-implanted silica absorbs strongly.

Figure 1 a shows schematically the setup for $z$-scan and absorption measurements. In position (1) power meter D1 measured the total incident power on she sample $S$, in position (2) it monitored the power reflected from the beamsplitter BS while the sample was irradiated. It was mounted on a self-centering base for accurate repositioning at positions (1) and (2). Power meter D2 measured the transmitted power.

For absorption measurements lens L2 was mounted behind the sample to focus all transmitted light on D2. The laser spot on the sample had about $0.5 \mathrm{~mm}$ diameter and the total laser power was varied to measure absorption as function of intensity.

For the z-scan lens $\mathrm{Ll}$ with $\mathrm{f}=150 \mathrm{~mm}$ was mounted behind the beamsplitter and the sample was mounted on a motorized railtable, so it could be moved parallel to the beam axis through the focal point of the lens to vary the intensity on the irradiated area of the sample. Figures 1 b, c give a qualitative explanation of the z-scan method, details are described by M.Sheik-Behae et al. [7]. Figure $1 \mathrm{~b}$ explains how the nonlinear index of refraction, $\mathrm{n}_{2}$, leads to self focussing. The incoming plane wave has a Gaussian radial 
intensity profile, $I(r)$ ( $r$ : distance from beam axis ). This causes a radial profile for the total index of refraction, $n(r)$, and speed of light, $v(r)$, in the saniple (no: linear index of refraction; $c_{v}$ : vacuum speed of light; different from ref. [7] $n_{2}$ in this work refers to the nonlinear index independent of units):

$$
n(r)=n_{0}+\frac{n_{2}}{2} * I(r), v(r)=\frac{c_{v}}{n(r)}
$$

The speed profile distorts the plane wave approximately like a lens. Figure $1 \mathrm{c}$ explains how the intensity on detector D2 changes as the self focussing sample, shown as lens, is moved through the focal point of lens L1. In position (a) the sample increases divergence of the outgoing beam, so the intensity on detector D2 desreases, in (b) it has no effect, in (c) it decreases diverger.'s, so intensity increases. For positions far from the focal point the intensity on the sample itself is so low, that self focussing can be neglected and the intensity on the detector is the same as in (b).

The laser induced fluorescence spectra were taken with a double grating spectrometer designed for high rejection of stray light from the laser.

\section{Results}

\section{Absorption of Ti-implanted silica}

We observed a number of puzzling features in the absorption and reflectivity spectra of the sample. Figure 2 shows that the absorption of Ti-implanted samples strongly depends on the ion dose. Between $1 \cdot 10^{16}$ and $6 \cdot 10^{16}$ ions $/ \mathrm{cm}^{2}$ is a threshold for the dose, where absorption jumps from about $15 \%$ to $30 \%$. As shown below, above this threshold also the first signs of self-focusing were observed.

At the power levels used (100 to $1300 \mathrm{~mW}$ ), absorption for the high dose samples is independent of the incident power. The low dose samples show saturation, absorption drops from $17 \%$ to $12 \%$ as power increases from minimum to maximum. Measurements of reflection, to be published elsewhere, show the onset of saturation more clearly. 


\section{Laser-induced fluorescence (LIF)}

A second potentially interesting property of these materials is that the ion-implanted layer exhibits LIF in a broad range, and is thus a prima facie cindidate for tunable solidstate laser material. In recent years, $\mathrm{Ti}^{3+}$ doped crystalline sapphire has been intensely developed as a laser host [8]; it exhibits a broad fluorescence in the near-infrared, a region where laser dyes are either non-existent or have low gains.

We have observed moderately intense LIF for samples implanted with $\mathrm{Ti}, \mathrm{Bi}$ and $\mathrm{Cu}$. Figure 3 shows a typical spectrum for $\mathrm{Ti}$. Spectra for $\mathrm{Bi}$ and $\mathrm{Cu}$ implanted samples look nearly identical, with the peak maximum shifted by $10 \mathrm{~nm}$ to lower wavelength for $\mathrm{Bi}$ and by $30 \mathrm{~nm}$ to longer wavelength for $\mathrm{Cu}$. The samples do not show fluorescence over the full implanted area, but only a few spots on each sample of about $1 \mathrm{~mm}$ diameter emit ligth. The mechanism leading to fluorescence is not clear yet. The similarity of the spectra for these different ions indicates that processes independent of the type of ion lead to fluorescence. Currently the role of defects like $E^{\prime}$ centers is being investigated.

\section{Nonlinear index of refraction}

Among the most striking phenomena observed in these materials is a dosedependent nonlinear index of refraction. Figure 4 shows the results for a $\mathrm{Ti}$ and a $\mathrm{Cu}$ implanted sample (both $6 \cdot 10^{16}$ ions $/ \mathrm{cm}^{2}$ each side). The intensity on detector D2 first drops, indicating positive self-focusing or positive $\mathrm{n}_{2}$, and then rises steeply as the sample crosses the focal point. The absolute value of $n_{2}$ can be calculated from the valley to peak ratio [7] and is of the order $10^{-5}$ esu (or $10^{-11} \mathrm{~m}^{2} / \mathrm{W} / \mathrm{n}_{0}$ in MKS units) [9].

The curve for the $\mathrm{Cu}$ implanted sample has a significant substructure on the leading and trailing edge. We have two possible explanations for this, none of which can be ruled out without further experiments. One is formation of colloidal copper; the particles in the colloid have different sizes leading to nonlinear bleaching at different light intensities. The 
other is constructive and destructive interference between the two implanted layers on the front and back side of the sample, but that leaves the question why the Ti implanted sample does not show any structure.

\section{Conclusions}

We have shown that implanted layers exhibit a number of interesting active optical properties in addition to the change in linear index of refraction which accompanies the ioninduced densification of an implanted layer. These properties may well make ion implantation a useful new way to modify silica for light sources and active optical elements. However, the effects of radiation-induced defects must be thoroughly understood before any such applications are possible. Finally, we note that it may also be possible to exploit the nonlinear optical effects to study the interaction between the implanted ion and its environment in ways which are inaccessible to traditional methods of radiation-damage analysis, such as electron paramagnetic resonance.

\section{Acknowledgements}

The research at Vanderbilt University was supported in part by the National Science Foundation under contract DMR-85-13731 and by the Office of Naval Research under Contract N00014-87-C-0146. The ion implantation facility and staff at the Oak Ridge National Laboratory are supported in part by the Division of Materials Science, Department of Energy under contract DE-AC05-840R21400 with Martin-Marietta Energy Systems, Inc.

\section{DISCLAIMER}

This report was prepared as an account of work sponsored by an agency of the United States Governanent. Neither the United States (jovernment nor any agency thereof, nor any of their employees, makes any watranty, express or implied, or assumes any legal liability or responsibility for the accuracy, completeness, or usefulness of any information, apparatus, product, or process disclosed, or represents that its use would not infringe privately owned rights. Reference herein to any specific commercial product, process, or service by trade name, trademark, manufacturer, or otherwise dexes not necessarily constitute or imply its endorsement, recommendation, or favoring by the United States Government or any agency thereof. The views and opinions of authors expressed herein do not necessarily state or reflect those of the United States Government or any agency thereof. 


\section{Reference}

(1) P. D. Townsend, Rep. Prog. Phys. 50 (1987) 501

[2] R.A. Weeks and G. Whichard, J. Appl. Phys. 67 (1990) 7526

[3] R. F. Haglund, Jr., H. Mogul, R. A. Weeks and R. A. Zuhr, submitted to J. NonCryst. Solids (1990)

[4] R. A. Weeks, "Interaction of Radiation with Materials", ed. A. Bishay and D. Griscom, J. Non-Crystal. Solids 40 (1980) 87

[5] H. Hosono et al., J. Non-Cryst. Solids 120 (1990) 250

[6] H. Hosono and R.A. Weeks, submitted to Phys. Rev. B (1990)

[7] M. Sheik-behae, A. A. Said and E. W. Van Stryland, Opt. Lett. 14 (1989) 955.

[8] P. F. Moulton, J. Opt. Soc. Am. B 3 (1986) 125.

[9] L. Yang, K. Becker, R.F. Haglund, Jr., and R.A. Weeks, Bull. Am. Phys. Soc., 35 (1990) 1530

\section{Figures}

Figure 1, Experimental Apparatus and Explanation of z-Scan

Figure 2, Absorption of Ti Implanted Fused Silica

Doses $\left(1 \cdot 10^{15}\right.$ ions $\left.\cdot \mathrm{cm}^{-2}\right): \quad 0=60, \Delta=60,+=10, x=3, *=1$

Figure 3, LIF-Spectrum of Ti Implanted Fused Silica

The structures at the ends of the spectrum are from stray light of the laser

Figure 4, Results of z-Scan for Pure, Ti- and Cu-Implanted Fused Silica 


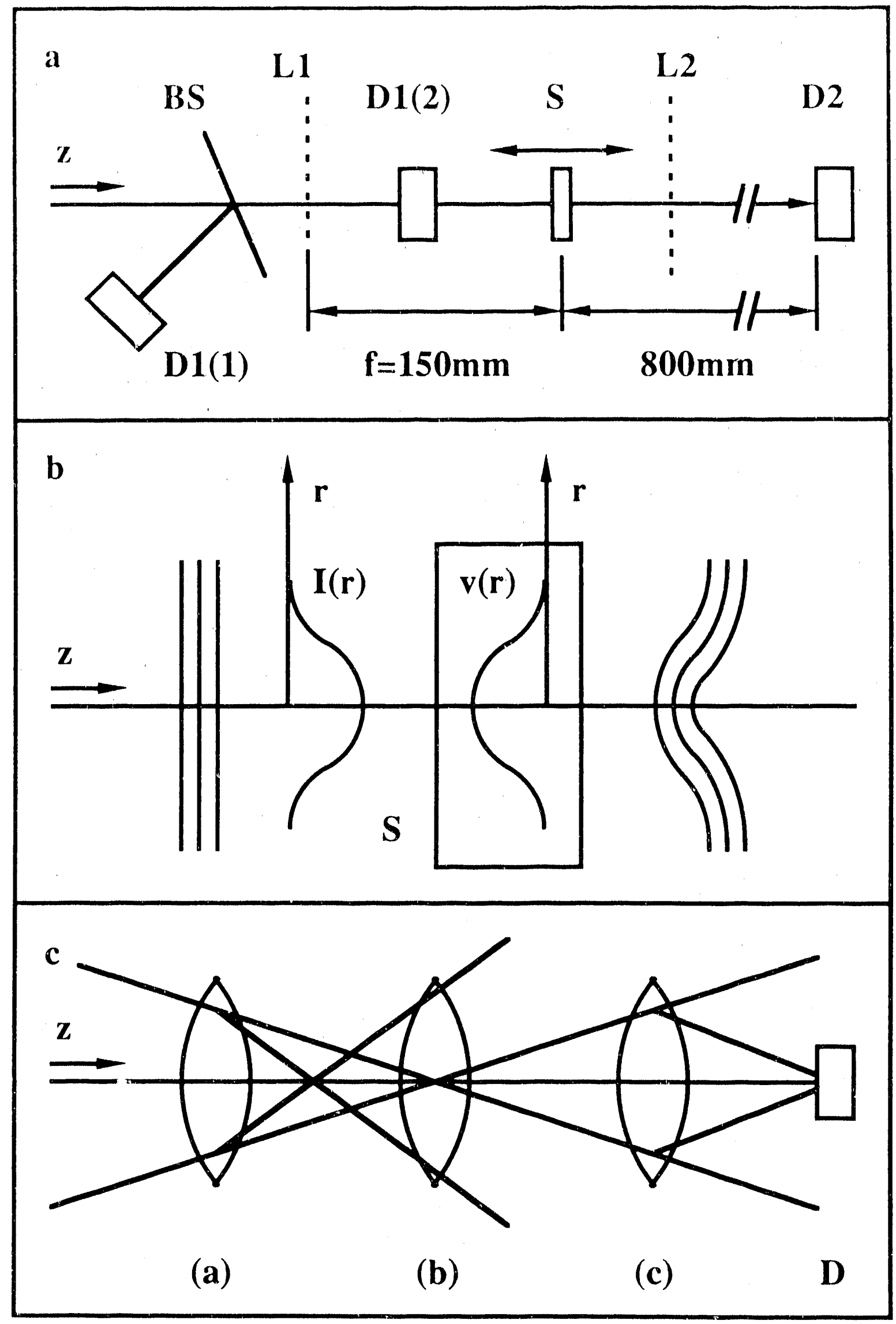

figure 1 , reduce to single column width 


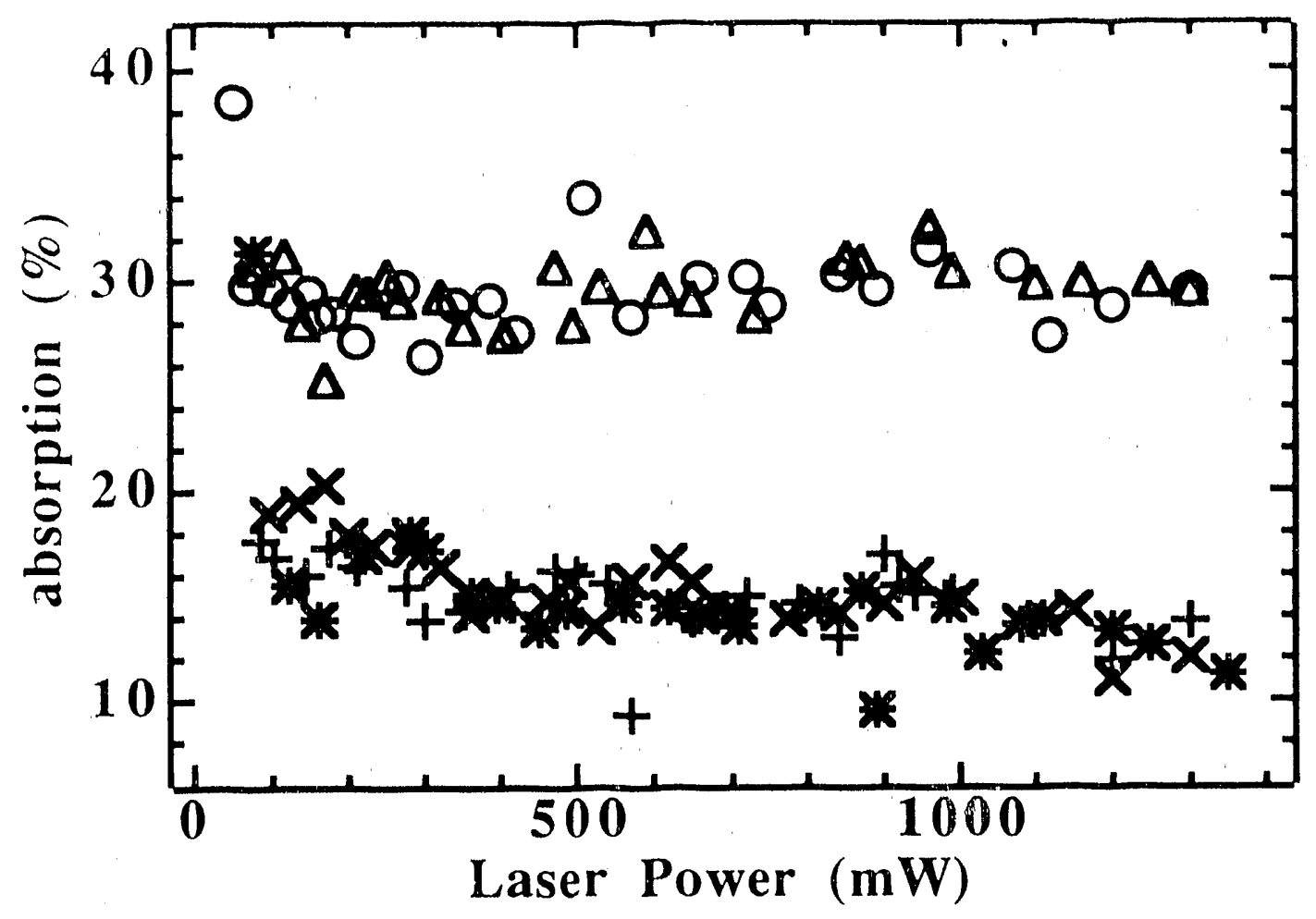

figure $\mathfrak{B}$, reduce to single column width 


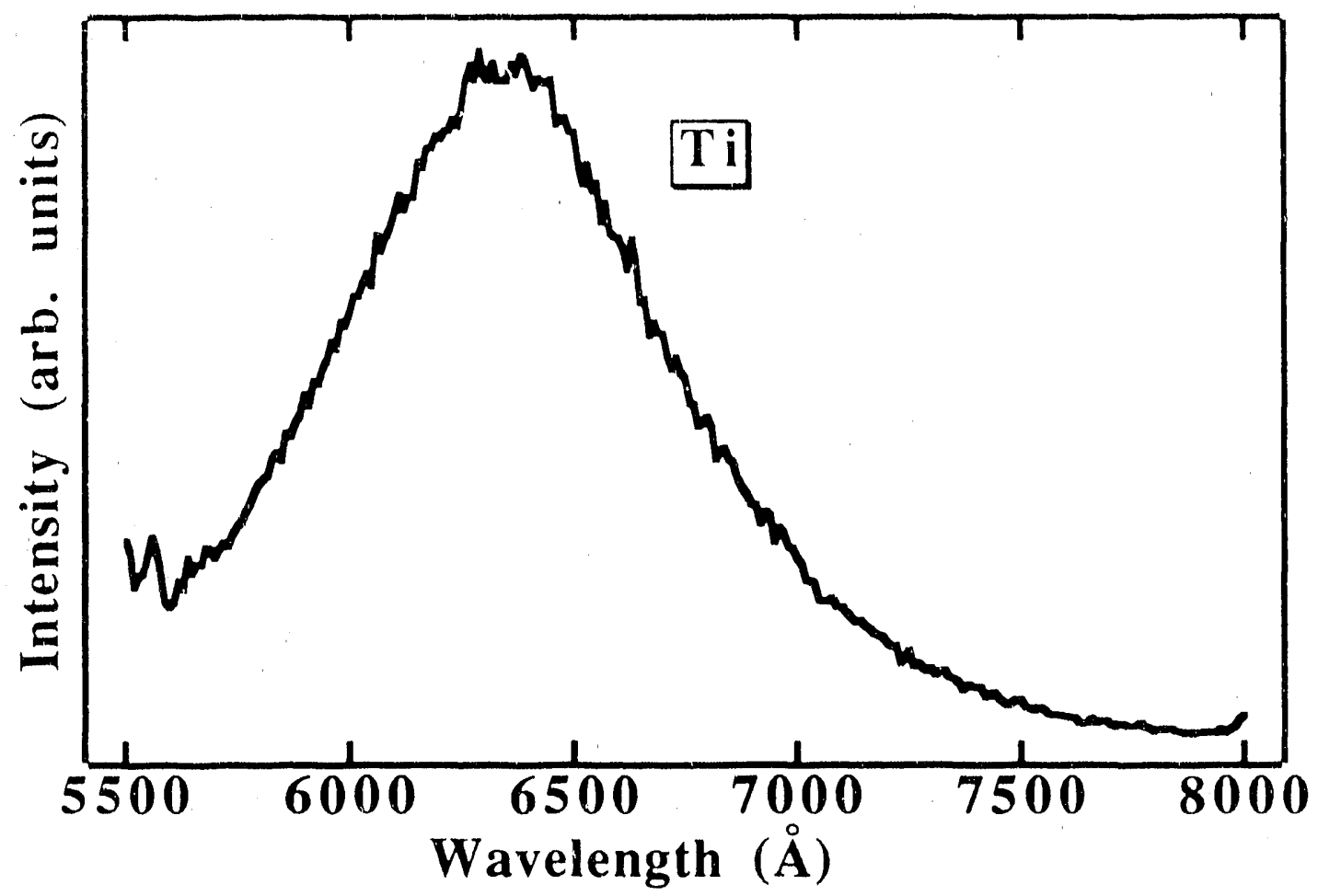

figure reduce to single column width 


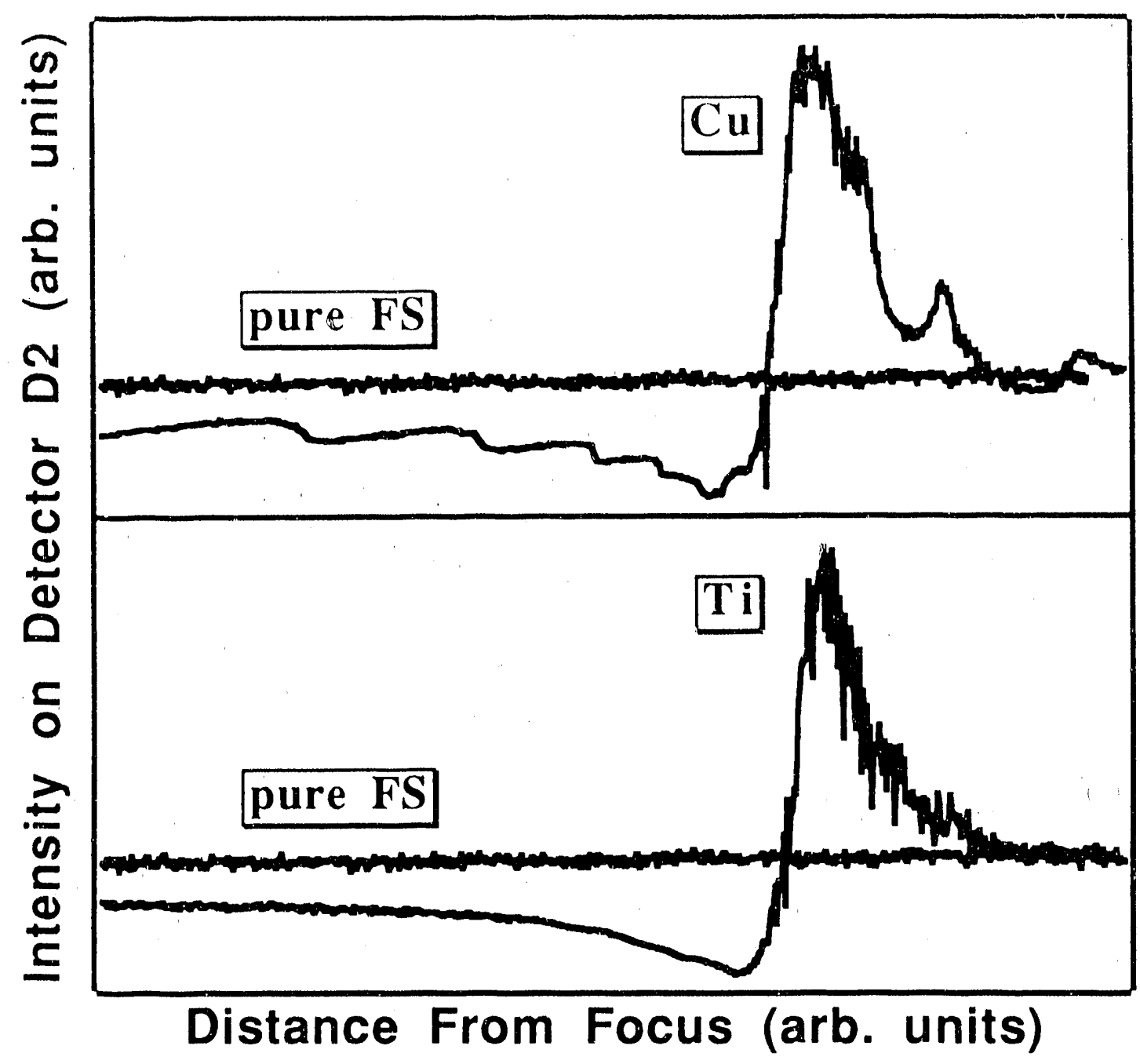

4

figure reduce to single column width 

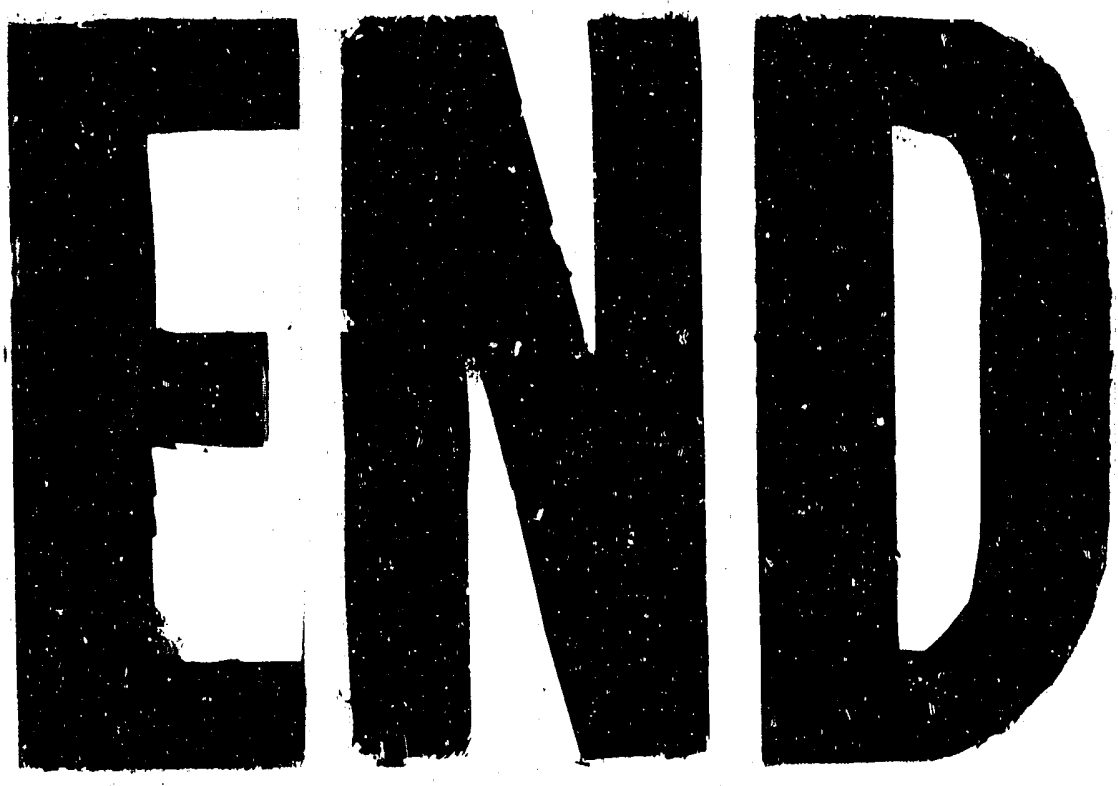

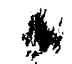
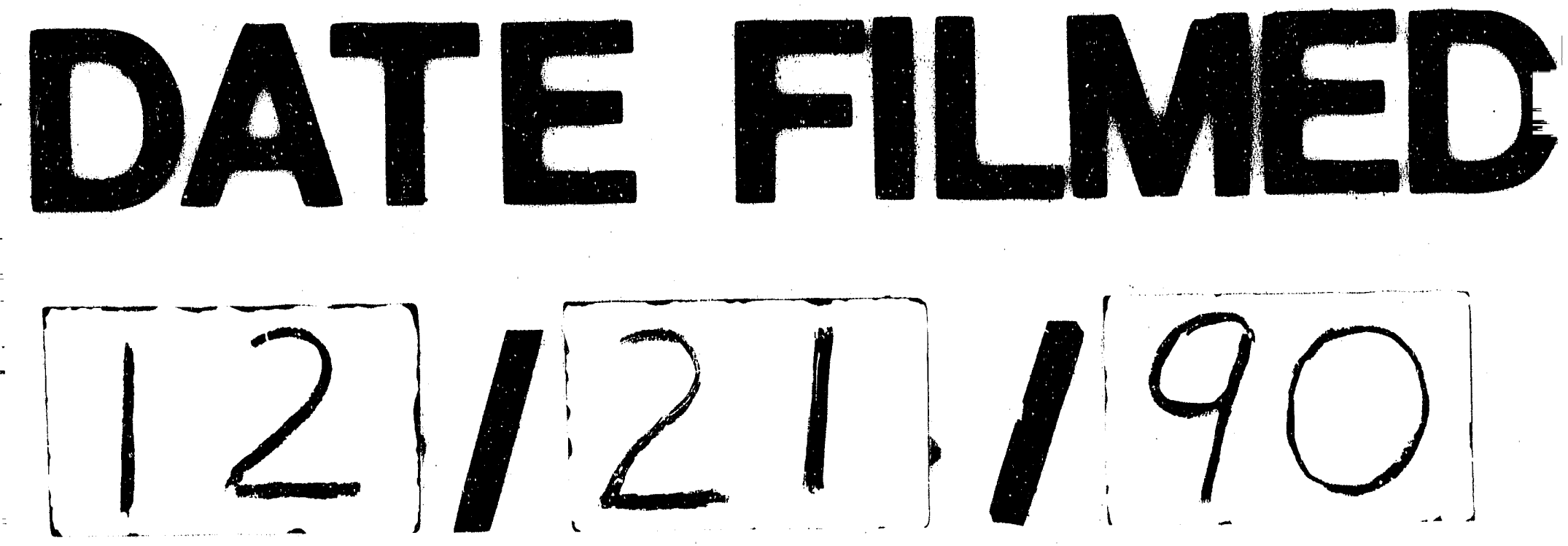